\title{
LOCATING DIGITAL LITERATURE IN WORLD LITERATURE: A CASE OF QUARTERLY LITERARY REVIEW SINGAPORE
}

\author{
Kristiawan Indriyanto \\ Gadjah Mada University \\ kristiawan.i@ugmail.ugm.ac.id \\ DOI: https://doi.org/10.24071/ijhs.2018.020103 \\ received 20 July 2018; revised 1 August; accepted 3 September 2018
}

\begin{abstract}
Although not to the full extent of South or East Asian literature, Southeast Asian (SEA) literature written in English has begun to reach wider prominence. It is important to underline that SEA literature have begun to embrace online or digitalized literature to complement the existence of printed literature. In line with the rising popularity of digital literature, this paper highlights the annual publication of Quarterly Literary Review Singapore (www.qrls.com) which encompasses several literary genres, from poetry, short stories and literary criticisms. Although originally established to raise the awareness regarding Singaporean literature, later publication has extended its scope into South East Asian and even diasporic writers. Through reading on several short stories in this annual publication, this paper emphasizes two main concerns. (1) What are the prevalent values and themes addressed by the (selected) short stories published therein and (2) How does the existence of digital literature problematizes the concept of world literature as it is theorized by Goethe and Damrosch? The analysis concludes that digital short stories published in www.qrls.com offer broad varieties of themes which enrich South East Asian literature field and should be considered into discussion regarding world literature as classroom materials.
\end{abstract}

Keywords: World literature, South East Asian Literature, digital literature

\section{Introduction}

In this modern era, English has been used as the language for global communication in which literature as one media of transmitting information is not an exception. The prominence of English as global language makes the circulation of literature easier as literary works now circulates in multiple directions, no longer limited from the metropolitan center to the colonial periphery. (Damrosch, 2009-, p. 106) Moreover, as a shared language, literature written in English functions also to foster intercultural communication among its readers. In the preface of A Rainbow Feast: New Asian Short Stories, an anthology of Southeast Asian short stories, Quayum remarks that 
literature in English is...not confined to a culture-tight compartment and therefore, it can help establish better understanding between various ethnic groups and nations through the articulation, appreciation, and understanding of each other's values, histories, and cultures (2010, p. 25)

Among Asian Literature in English, it can be seen that South and East Asian literature has a marked advantage in pioneering the use of English and also their longevity in literary production. As early as 1910s, the famous Rabindranath Tagore won the Nobel Prize in literature with the translation of his poems such as Gitanjali, Manasi, and Sonar Tori. Tagore's recognition in the West is soon followed by a Japanese writer, Ryunosuke Akutagawa through his short stories, Rashomon (1915) and Yabu-no-Naka (In a Grove). Akutagawa is noted for embracing modernist characteristics which dismantle the archetypical genre of the Showa period (Lippit, 1999, p. 30). Besides poetry and short stories, novel also flourishes as one genre among South Asian literature. During the colonial period, Ahmed Ali's Twilight of Delhi (1940) recalls the glory days of India before the advent of the Western colonizer, throughout "the era of Kauravs, Pandavs...Babur...Humayun, and Jahaghir." (1940, p. 4)

Specifically focusing on SEA countries, Singapore has been a leading proponent in using English as the language used in literature production. Summarizing the growth of Singapore as an English-speaking country, a fact highlighted also in their literature, Patke notes that "the first attempts of poetry in English in the late 1940's.... is synonymous with the growth of Singapore as a small, rapidly modernizing metropolis" (2000, p. 293). Several notable pioneers of Singaporean literature, especially poems are Wang Gungwu's Pulse (1950), Litmus Ones (1958) and 30 Poems (1958). In this contemporary era, English continues to be prevalent as the primary language of Singaporean literature as seen in the publication of several notable novels such as the Art of Charlie Chan Hock Chye by Sonny Liew in 2016 and also Simon Tay's City of Small Blessing (2009).

The development of Singaporean literature also encompasses literature which is uploaded online or known as digital literature. This phenomenon can be seen in annual publication of a Singaporean online journal entitled Quarterly Literary Review Singapore (www.qlrs.com). Ever since its first issue in October 2001, this online journal consistently publishes their annual yearly publication with the most recent issue of Vol. 17 in April 2018. Although originally intended to "promote the literary arts in Singapore, to stimulate the feedback mechanisms in the literary scene, and to develop Singaporean writers to international standards", in its expansion this journal has accepted submission from other SEA writers, diasporic writers and even Western expatriates. Encompassing a wide spectrum of literary genre from poetry, short stories, essays and literary criticisms, the annual publication is reviewed by a board of editors to insure the quality of the online publication. By analyzing several short stories published online in www.qlrs.com, this paper aims to shed some insight on the incorporation of digital literature into world literature.

How Singaporean literature has begun to embrace the development of digital literature can be seen as one solution to bridge the gap between SEA and other Asian literature. In this modern era where everything is digitalized, literature does not only circulate by their printed version but also by the digital copies, one 
notable example being Google Books. Sanz, for example, considers that the launching of Google Books in 2004 is "the symbolic turning point when the techniques of storage, transfer, and processing of information became a must on a global scale." (2017:16) Moreover, several digital literature especially the ones uploaded in QLRS website are primarily intended for digital readership and no printed version is available. Different from the 'classical' printed model of literature such as novels, anthologies and romance, digital literature in this case is a form of literature born in the digital world, i.e., the text was created on a laptop for example, and uploaded to a blog or webpage for online reading.

Although digital media offers one avenue to popularize SEA literature, several questions should firstly be addressed regarding digital literature. Firstly, what about the quality of the literature itself? Indeed, anyone can write and then upload either on their personal blogs or social mediawith which some kind of editorial control remains needed to differentiate between "high" and "low" literature. Secondly, what about the themes? And lastly, how to locate digital literature as one example of world literature? Several leading theorists of world literature such as Goethe, Damrosch and Moretti theorize their differing definition of world literature based on printed literature. The circulation of digital literature differs significantly compared to the classical one, as basically after uploading to the internet the texts are able to read globally. Henceforth, the existence of digital literature then problematizes the previously accepted convention of world literature.

\section{Method}

This subsection is intended to contextualize two main aspects regarding the definition of digital/electronic literature and world literature. The development of electronic literature is inseparable with the rapid ascent of technological advancement, especially in the field of computer and internet or mobile networking. As summarized by Montfort (2007:172), computer enables digital literature to represent events by directly outputting narrative text, graphics and sounds. This statement confirms that digital literature can take full advantages of their medium by simultaneously provides its readers with audio-visual reception. Moreover, digital literature is advantaged by their connection with the internet, in which basically "narratives of personal experience is now possible to be shared with millions of strangers." (Ryan, 2005, p. 18). Since anybody with an internet connection can publish his or her own weblog, there is a great variety in the quality, content, and ambition of weblogs, and a weblog may have anywhere from a handful to tens of thousands of daily readers. (Walker, 2005, p. 97). The increasing influxes of digital literature can threaten the dominance of printed literature. Some even go as far to suggest "pronouncements of the death of the novel became increasingly frequent and strident as the twentieth century progressed and varieties of visual and electronic media became more influential. (Mancing, 2005:538)

Moving into the discussion of world literature, this concept has been questioned and constantly revised since its conception. World literature is first theorized by Goethe through his concept of Welt literature which anticipates the emergence of a universal world literature. (Pizer, 2000, p. 215) Writing in the 1800 s, Goethe is convinced "that a universal world literature is in the process of 
formation" (cited in Prendergast, 2004, p. 3) that literature must not only be read and circulated in their nation but should be able to reach wider, even global audience. Goethe's seminal concept is further refined by Damrosch's assertion that world literature encompasses all literary works that circulate beyond their culture of origin, either in translation or in their original language." (2000, p. 9). Moreover, in this modern era, most literature circulates via translation. (Damrosch, 2009, p. 65) which highlights the easier accessibility of literary production among the global community.

Damrosch highlights the notion that circulation of world literature is inseparable with the issue of publication. Book publishers are the one that firstly select whether a manuscript is deemed suitable for publication and whether it will be able to attract wider readership. Moreover, the circulation of literature such as novels, anthologies of poetries and also short stories from their country of origin has been a pivotal landmark in the informational exchange since the colonial era especially the how novel as the pre-eminent example of Western literature is transmitted from Europe to Latin America. (Siskind, 2010, p. 336). It can be asserted that circulation and publication plays quite a notable role in world literature, which makes this classical model of literature differs from the digitalized one. Damrosch's statement that any literature becomes world literature whenever it is circulated beyond their country of origin is scrutinized when it concerns digital literature as it is uploaded into a virtual media with global scope. It is particularly emphasized through Sanz's statement; digital literature is "literature born to circulate on the Internet" $(2017$, p. 16) that affirms the primacy of internet in circulating digital literature.

Locating digital literature within world literature, it is clear that the previously accepted definition of world literature still does not recognize the increasing prominence of digital literature. It is worrying, as even as early in the turn of the millennium Apparadurai already asserts that "public spheres are increasingly dominated by electronic media" $(2000$, p. 22$)$ in which literary field is not an exception. Yet, the emergence of digital literature is still rather neglected by the discussion of world literature specially concerning canonical world literature. The concept of 'opening up the canon' (Gulliory, qtd in Damrosch, 2003 , p. 8) by complementing the classical canonical literature with lesser known literary production should also begin to incorporate the emergence of digital literature. Circulation and publication, as previously asserted by Damrosch become one problematic area to incorporate digital literature especially into canonical world literature. As the screening for publishing online literature is negligible compared to the printed world, skepticism then arises whether digital literature is qualified enough to be considered an example of canonical world literature. To further contribute in the ongoing debate regarding the incorporation of digital literature into the canonical world literature, this paper analyzes several short stories published online in Quarterly Literary Review Singapore and argues that the stories published there are worthy to be considered as canonical world literature. 


\section{Findings and Discussion}

This section focuses on analyzing several short stories published online in www.qlrs.com with two major emphases : (1) identifying several overreaching themes and values addressed in several texts and (2) arguing that the definitions of world literature as previously theorized by Goethe and Damrosch still do not cover the emerge of digital or electronic literature. In turn, this paper argues that the short stories uploaded in Quarterly Literary Review Singapore (henceforth QLRS) should be placed into consideration when concerning canonical world literature especially Asian Literature in English. QLRS has been a prolific journal, since the seminal launching of QLRS website in 2001, there has been 17 volumes of QLRS which signifies the 17 years of this online journal. Moreover, as each volume in one year encompasses three until four publications, it can be noted that this journal has uploaded sufficient works, the website itself summarizes a total of 252 short stories. From this anthology, this paper aims to provide a brief chart of overreaching themes from several short stories.

One of the most prevalent theme of QLRS publication is nostalgia concerning the past and how the shifting timeframe alienated the protagonist in the present era. One short story, Oh-Chien by Lydia Kwa focuses on the main character, Millee's reminiscence with oh-chien (fried oyster) and how her recollection of eating oh-chien in the past differs significantly with the present era. "She associated oyster omelletes with her childhood" and how "this scene reminds her with how it used to be in Singapore 40 years ago." (Kwa) She recalls how the older scene of "a string of naked light bulbs suspended between poles of the cart, the charcoal-fuelled fire" is in total contrast with the present Melaka, "Jalan Hang Jebat had transformed into a tourists' Jonker Walk, free of cars and trishaws, packed with vendors selling goods made in PRC."

Another short story, Mrs Chan's Wedding Day also places the character's reminiscence of the past a central theme. In this story, the unnamed main character contrasted between Singapore and Hong Kong between Singapore and Hong Kong regarding preservation of Chinese custom and culture. The unnamed protagonist's housemaid, Mrs Chan will not be working on New Year's eve, as she was busy "bringing the wedding cakes round as an old Chinese custom." (Poon, 2002) This tradition, unfortunately had stopped in Singapore around 1970, after the time of "Tower Records and MTV" (Poon, 2002). On the contrary, this dying tradition of visiting families and bringing wedding cake remains continued in Hong Kong, where the main character goes to school after leaving Singapore.

Though several stories portray their place as something nostalgic to pine for, another story contextualizes their homeland as old-fashioned and conservative compared to the previous short stories. One example in Jasmine's Father by Paul Tan, the conflict that occurs between Jasmine and her father is fueled by Jasmine's dissatisfaction with the sexist and misogyny driven Singaporean society. Jasmine's struggle in Singapore starts when her boss, a Chinese former government scholar was threatened by Jasmine's "outspoken manner, the speed of her decisions, and her strong presentation skills."(Tan, 2001) All those abilities which her boss considers should only be acquired by male- marginalizes Jasmine and led her to immigrate abroad to Canada. Moreover, her disdain with Singaporean which later further extended to other Asian men further flourishes. 
She increasingly chooses to interact with Canadian men, rather than men from the Asian community there. Those guys are so with it, articulate and sporting, she declared, compared to Singaporean men who were graceless, guarded chauvinists with the charm of a flea. (Tan, 2001)

Among the short stories uploaded in QLRS, one notable short story is Fathers, written by Ioannis Gatsiounis, a Greek-diasporic writer, a New York native and now living in Malaysia. His cosmopolitan background provides a fresh outlook of Singaporean community as it is now perceived from a westerner's eyes. In this story, Gatsiounis contextualizes how an unnamed male protagonist from a foreign European country lives his life as a freelance in Singapore in a decrepit neighborhood.

Living poorly in a back-alley, next to the spandex-clad old women harrumphing their way through stacks of cardboard, the Cantonesespeaking junkies flashing sheathes of pirated DVDs from their seats along the curb; or Jamu, the limbless boy wonder who snatched up used condensed-milk cans with his teeth (Gatsiounis, 2005)

From the aforementioned passage, Gatsiounis subverts several stereotypically tropes about Westerner who either lives or visits Asia. A research by Dewi (2014, p. 136) illustrates that the genre of Australian colonial fictions in several novels such as Five Skull Island and Other Tales of the Malay Archipelago (1897), Castro's Last Sacraments (1900) and Flight into Paradise explores the Westerner's lack of understanding of the local traditions and customs in Asia. Even in the modern era, several portrayal of Westerners in Asia still abide to the "imperial eyes" (Pratt, 1994, p. 8-9) trope, where Asia is perceived through Euro centrist perspective. One research on Christoper Koch's fictions, especially his novel the Year of Living Dangerously finds out how the protagonist, as the Westerner who visits Asia is disorientated and feeling loss in a strange place and his desire to "regain knowledge and his sense of place in the world" (Habel, 2007, p. 49).

The portrayal of Gatsiounis' main character in Fathers explores living condition of Singapore from a different angle. His protagonist is a freelancer trying to do odd-jobs as his occupation as a writer is inadequate instead of going to "the Sheratons, the KFC's, the mega malls and light rail".(Gatsiounis, 2005) During his stay in Singaporean's suburban, he befriends several of his room-mates and neighbors, Razali, a Muslim by name only- who smokes and drinks powdered Milo during the holy month of Ramadhan and Nadhira, who he has a relationship with. Gatsiounis explores the dynamics of Singapore as multi-ethnic society where the Indians, Malays, and the Chinese are the majority groups. Gatsiounis portrays his protagonist as a more tolerant person towards the racial diversity in Singapore, which is contrasted with the character named Charlie Wong. On the contrary with Gatsiounis' unnamed protagonist, Wong is an unashamed racist with statement that "the Chinese were a gruff money-minded minority. The Malays were said to be passive and courteous, to cherish God and family and bumming around more than money." (Gatsiounis, 2005) The racist character in Fathers is not the white male protagonist but instead the native Singaporean who is dismissive towards other races in this island, the Malays and the Chinese.

From the prior discussions, it can be concluded that the short stories published in QLRS website enriches SEA literature discussions by providing 
different angles of perceiving Southeast Asia especially Singapore. Several stories offer contrasting portrayal of Singapore, either through reminiscence of the forgotten traditions and customs in Singapore, or depicting the still rampant sexism and misogyny as prevailing factor which causes Jasmine in Jasmine's Father to emigrate toward Canada. Subsequent paragraphs will problematize more about how online literature, as illustrated through QLRS short stories should also be incorporated into canonical world literature especially in Asian Literature in English.

Returning to the second question addressed by this paper, the previous discussion of world literature by Goethe and Damrosch still do not accommodate the emergence of electronic literature. Damrosch himself acknowledges that what constitutes world literature is not a fixed definition or only accommodates certain canonical works but instead is a mode of circulation and of reading (2003, p. 5). In Damrosch's opinion, world literature is not a settled state and instead unstable in flux. He reviews the development of world literature, while previously the notion of "world literature" only signifies Western literature, nowadays the term "opening up the canon" has incorporated non-Western writers into the anthology of World English literature. As asserted by Gurray, (qtd in Damrosch, 2003, p. 8) to "open the canon" we must have to modernize it, not just focusing on the early or classical literature but also to include the later works. The "opening up of the canon" have begun to accomodate hitherto unknown including non-Western literary works into canon, either as "hypercanon, countercanon, or shadow canon" (Damrosch, 2006, p. 45). Although "opening up of the canon" has been beneficial for minor and third-world writers, few steps have been taken regarding the incorporation of digital literature as example of world literature. (Tabbi, 2010)

At this point, it is important to underline the differences between world literature and canonical world literature. Both Goethe and Damrosch's previous concept regarding the circulation of literature beyond their country of origin is more particularly biased toward world literature instead of the canonical world. The emergence of digital literature itself is a problematical concept concerning world literature as after the literature is uploaded into the internet itself it instantly becoming world literature. As internet basically is owned by the world community -hence the name world wide web (WWW), digital literature by definition is already circulated beyond their country of origin. Hence, speaking about world literature and the canonical one, it is important to differentiate between the two of them. In this paper's perspective, the literature published by the QLRS should be taken into consideration regarding canonical world literature although some consideration must also be taken. Basically, literary works published outside their countries' boundaries can be classified as canonical works after it passes several criteria, mainly whether it has already been taught as teaching material either at university or high school level and secondly whenever it is anthologies. In the case of digital literature uploaded in QLRS, this paper states that the selected short stories should be considered as material for Asian Literature in English.

This present study argues that the selected short stories uploaded in QLRS encompasses the working definition of SEA literature as proposed by Dewi (2014). In her article, Dewi mainly explores how to define Asian literature in English, and this study reduces the scope into Southeast Asian literature instead of 
Asia as a whole. She addresses several characteristics of (Southeast) Asian Literature as follows,

(a) To portray (Southeast) Asian people, places, and experience

(b) To depict values, tradition, principles associated with (Southeast) Asian society in the past to the present

(c) Intended to meet (Southeast) Asian readership

(d) Written by writers of (Southeast) Asian origin or with (Southeast) Asian background (2014, p. 138)

As previously explored, the selected QLRS short stories abide to the working definition of (Southeast) Asian literature as proposed by Dewi. The selected short stories contextualize living experience in Southeast Asia especially Singapore from various angles and diverse outlook. Oh-Chien and Mrs Chan's Wedding puts forward the issue of nostalgia, how modernity has changed the street of Singapore into business-oriented district catered for tourist and the extinction of wedding tradition in the rapidly-developing Singapore. Another story, Jasmine's Father implores the reader that behind the façade of modern and Westernized Singaporean society, sexism and misogyny still entrenched and hinder the advancement of Singaporean females. Lastly, Fathers, although written by a Greek-diasporic writer does not portray Singapore from "imperial eyes" but instead gives an illustration of a struggling European in Singaporean suburban area. The varied and ranging theme such as the longing of the past, disillusionment with the modern society, rampant sexism and misogyny in Singaporean society and different portrayal of the white living in Asia makes QLRS literature worth considering in the curriculum of Asian Literature in English.

\section{Conclusion}

It can be stated that the emergence of digital literature enriches the discussions of world literature, especially SEA literature and should be considered. Digital literature can be one possible consideration for SEA literature to -which to say- catching up with the entrenched dominance of other regions in Asia such as East, South, or Middle East in world literary discussion. Yet, several problems still arise regarding the incorporation of digital literature into world literature and there should be a marked differentiation between world literature and canonical world literature concerning digital literature. Goethe and Damrosch's previous concept regarding world literature is too broad, as according to their definition any online literature since it has been uploaded in the web instantly become part of world literature. The notion of circulating literary works by the printed version is shattered by the entrance of internet as the primary medium of digital literature. This paper is in the opinion that classification should be done regarding the integration of digital literature into canonical world literature. Literature published online in reputable journal or academic forum such as QLRS has wide ranging themes, tackling various problems in SEA countries which makes the short stories worth considering as a classroom material especially in Asian Literature in English. It is hoped that this discussion shed some light regarding the position of digital literature in world literature. 


\section{References}

Ali, A. (1940). Twilight in Delhi: A novel. London: Hogarth Press.

Arjun, A. (2000). Modernity at large: Cultural dimension of globalization. Minneapolis: University of Minnesota Press.

Damrosch, D. (2003). What is world literature? Princeton: Princeton University Press.

Damrosch, D. (2006). World literature in a postcanonical, hypercanonical age." Comparative Literature in an Age of Globalization. Ed. Haun Saussy. Baltimore: The Johns Hopkins University Press.

Damrosch, D. (2009). How to read world literature. Chicester: Wiley-Blackwell.

Dewi, N. (2014). "In search of contextual and humanistic Southeast Asian literature in English." Celt: A Journal of Culture, English Language Teaching and Literature, 2(14), pp. 133-147. Retrieved from http://journal.unika.ac.id/index.php/celt/article/viewFile/318/305>

Gatsiounis, I. (2005). "Fathers" Quarterly Literary Review Singapore. 4(4) <taken from www.qlrs.com/story.asp?id=449>

Goethe, Qtd in Pizer, J. (2000). "Goethe's world literature paradigm and contemporary cultural globalization. Comparative Literature, 52(3) pp. 213227 < https://www.jstor.org/stable/1771407>

Goethe, qtd in Prendergast, Christopher. (2004). Debating world literature. London: Verso.

Habel, C.S. (2007). "Shadow on Screen The Wayang Kulit in The Year of Living Dangerously." Journals of the Association for the Study of Australian Literature. $\quad 7, \quad$ pp. $46-58$

https://onlinelibrary.wiley.com/doi/pdf/10.1111/j.0022 3840.1994.2801_163.x>

Kwa, L. (2017). “Oh-Chien” Quarterly Literary Review Singapore. 16(3). <taken from http://www.qlrs.com/story.asp?id=1355>

Lippit, S. M. (1999). "The disintegrating machinery of the modern: Akutagawa Ryunosuke's late writing." The Journals of Asian Studies. 58(1), pp. 27-50< $<$ https://www.jstor.org/stable/2658388>

Mancing, H. (2005). "The Novel" in Routledge Encyclopedia of Narrative Theory. Ed. David Herman, Manfred Jahn and Marie-Laure Ryan. London: Routledge.

Montfort, N. (2007). "Narrative and Digital Media" in the Cambridge Companion to Narrative. Ed. David Herman. Cambridge: Cambridge University Press.

Patke, R.S. (2000). "Poetry in English from Singapore" World Literature Today, 74(2), pp. 293-299 <http://www.jstor.org/stable/40155573>

Poon, W. (2002). "Mrs Chan's Wedding Day." Quarterly Literary Review Singapore, 2(1). <taken from http://www.qlrs.com/story.asp?id=249>

Quayum, M.A. (2010). A rainbow feast: New Asian short stories. Singapore: Marshall Cavendish International.

Ryan. M.L. (2005). "On the Theoretical Foundations of Transmedial Narratology" in Narratology Beyond Literary Criticism. Ed. Jan Christoph Meister. Berlin: Walter de Gruyter.

Sanz, A. (2017). "Digital Literatures Circulation: Testing post-Bourdieu Theories." Neohelicon. 44, pp. https://link.springer.com/article/10.1007/s11059-017-0378-9> 
IJHS, e-ISSN 2597-4718, p-ISSN 2597-470X, Vol. 2, No. 1, September 2018, pp. 22-31

Siskind, M. (2010). "The globalization of the novel and the novelization of the global: A critique of world literature." Comparative literature. 62(4), pp. 336360

< https://www.jstor.org/stable/40962923>

Tabbi, J. (2010). "Electronic Literature as World Literature; or, The Universality of Writing under Constraint" Poetics Today. 31(1), pp. 17-50.

< https://doi.org/10.1215/03335372-2009-013>

Tan, P. (2001). “Jasmine's Father" Quarterly Literary Review Singapore. 1(1). <taken from http://www.qlrs.com/story.asp?id=136> 